Social Perspective Taking: A Benefit of Bilingualism in Academic Writing Lisa $\mathrm{Hsin}^{1,2} \&$ Catherine Snow ${ }^{1}$

${ }^{1}$ Harvard University, ${ }^{2}$ University of Alabama

The final full-text publication is available at:

https://ink.springer.com/article/10.1007\%2Fs11145-016-9718-9 


\begin{abstract}
The task of writing arguments requires a linguistic and cognitive sophistication that eludes many adults, but students in the US are expected to produce written arguments starting in the fourth grade. Students from language-minority homes likewise must learn to produce such writing, despite their relatively limited experience with the English language, reflected in the availability of smaller mental lexicons and more restricted syntactic constructions. Yet some features of bilingual children's cognition, such as precocious development of theory of mind and strong metalinguistic awareness, might support the crafting of arguments in writing, where the explicit consideration of multiple points of view can serve to strengthen one's case for a claim. In this study we examine the incidence of social perspective-taking acts in the argumentative essays of language-minority and English-only students in Grades 4-6 and find that language-minority students match or surpass the English-only students on two critical measures of perspective taking (perspective acknowledgment and perspective articulation). We also explore possible connections between students' use of perspective taking in their argumentative essays and a validated formal measure of the same skill, uncovering different relationships between them in the two language groups. Connections to previously attested bilingual advantages and to the development of argumentation are discussed.
\end{abstract}

Keywords: perspective taking, sociocognitive development, adolescent literacy, bilingual advantage, language minority, persuasive writing, argumentative writing 


\section{Social Perspective Taking: A Benefit of Bilingualism in Academic Writing}

The pressure for students from language-minority (LM) homes to master the English language thoroughly and quickly is more pressing than ever (cf. Frantz, Starr, \& Bailey 2015), as American schoolchildren are now expected to write persuasive arguments starting in the sixth grade and rudimentary versions of the same in fourth grade (cf. National Governors Association Center for Best Practices \& Council of Chief State School Officers [NGAC] 2010). Yet the challenge of writing in this genre can be formidable. Argumentative writing differs in important ways from the more commonly taught — and commonly researched—narrative and expository genres. Writing in the narrative and expository genres already calls upon students to respect temporal/episodic and grammatical conventions that are distinct from the norms of conversation for which children most often put language to use. But in argumentative writing, authors must additionally coordinate claims with evidence, that is, must generate warrants, as well as explicitly consider (and ultimately dismiss) counterarguments (Kuhn \& Udell 2003), adding to the demands of the task. The linguistic and cognitive challenges associated with the task of argumentative writing might be expected to be virtually insuperable for LM students in particular (cf. Lee, Quinn, \& Valdés 2013). These students often have not had the benefit of early print exposure in English that might have facilitated their literacy development (Gonzalez \& Uhing 2008; McQuillan 2006), thus postponing or circumventing their academic success and their engagement with the broader intellectual community. On the other hand, research in cognitive psychology over the last several decades has documented some cognitive advantages that arise out of the bilingual experience (e.g., Prior \& MacWhinney 2010; Verreyt, Woumans, Vandelanotte, Szmalec, \& Duyck 2016), and in the current study we investigate whether those advantages might be manifested in this very challenging genre of argumentative writing. 


\section{Argumentative Writing Skill in LM Students}

The expectation that children should be able to write simple argumentative essays by

Grade 4 requires that they employ skills whose developmental trajectory has not been well studied in native English-speakers (cf. Llosa, Beck, \& Zhao 2011); a handful of recent reports on interventions that support (and thus implicitly document) the growth of argumentative writing skill (Dobbs 2014; Kuhn \& Crowell 2011; Kuhn, Zillmer, Crowell, \& Zavala 2013) start at sixth grade. The absence of studies on point is starker for the LM population, which is not differentiated from the broader population in any recent review of writing instruction, irrespective of genre (e.g., Graham \& Perin 2007; Newell et al. 2011). Given the "cognitive, linguistic, communicative, contextual, textual and affective constraints" (Matuchniak, Olson, \& Scarcella 2014, p. 973) involved in long-form text production and the further demands placed on writers of argumentative texts to produce a dual-perspective, evidence-supported series of claims (cf. Kuhn \& Crowell 2011), it is reasonable to predict that if research did distinguish Englishonly (EO) and LM student groups the outcomes for LM students would be relatively poor. Indeed, what is known about the development of writing does not bode well for LM students: In the U.S. population on the whole, poor outcomes in writing are associated with poverty and attendance at urban schools at the societal level (e.g., Battistich, Solomon, Kim, Watson, \& Schaps 1995; Walsh et al. 2014), and with limited vocabulary and limited engagement in literacy practices at the individual level (e.g., Foster, Lambert, Abbott-Shim, McCarty, \& Franze 2005). LM students are disproportionately vulnerable in both domains, and are particularly likely to show limited vocabulary skills in English and associated limitations in reading comprehension even after they have been reclassified as fully English-proficient (e.g., August, Carlo, Dressler, \& Snow 2005; Mancilla-Martinez \& Lesaux 2011). Unsurprisingly 
given the state of the literature on LM students' writing development across genres, to our knowledge no research has investigated their skills in argumentative writing expressly.

\section{Known Bilingual Benefits}

Nevertheless, the pragmatic and more broadly sociocognitive (cf. Snow \& Uccelli 2009) aspects of the practice of argumentation may do more than just challenge the linguistic competence of LM students. The call for considering counterarguments and supplying evidence for claims is crucially related to anticipating others' reactions and to adjusting one's perspective to align with a possibly more naïve reader. The utility of these tools in persuading a reader of one's position parallels the effect of the skills that bilingual individuals must employ in order to get around in everyday life: Bilinguals must grasp the language, and therefore the perspective, of others in order to communicate, since not everyone in their environment speaks both of their languages. In other words, bilinguals regularly exercise a conscious choice over what language they will use to address the people they come across (e.g., Deuchar \& Quay 1999).

Daily communicative pressure for perspective taking and language selection gives rise to improved control of cognitive processes, in particular executive functions (EFs), that arguably support the development of skills needed for the construction of a strong argument (cf. Kuhn, Hemberger, \& Khait 2016): a bilingual advantage (cf. Costa, Hernández, Costa-Faidella, \& Sebastián-Gallés 2009; Scaltritti, Peressotti, \& Miozzo 2015). In particular, bilinguals reliably surpass monolinguals in the development and application of executive control functions such as conflict monitoring (e.g., Costa et al. 2009; Qu, Low, Zhang, Li, \& Zelazo 2016) and interference suppression (e.g., Martin-Rhee \& Bialystok 2008; Yang \& Yang 2017), owing, many researchers argue, to the regular experience of calling up the linguistic structures of one language and suppressing the structures of the other (for a recent meta-analysis, see Adesope, 
Lavin, Thompson, \& Ungerleider 2010; for a recent review, see Bialystok, Craik, \& Luk 2012; for a more skeptical take, tempering but still supporting the claim of a bilingual advantage, see de Bruin, Treccani, \& Sala 2015). Although there are some circumstances in which appropriatelanguage responses are given that could be explained away without invoking cognitive control (e.g., "Jo hears an X word, Jo feels unreflectively compelled to respond in X language") even bilingual toddlers can use knowledge about what language(s) people in their environment speak to adjust their productions intentionally (Genesee, Boivin, \& Nicoladis 1996).

Evidence suggests that these early, frequent language selection experiences thus prompt the precocious development of theory of mind (ToM) - the ability to take another person as an (intentional) agent—in bilingual children (Chan 2004; Goetz 2003; Kovács 2009). Simple ToM is mastered by most typically-developing children by around age four, after a protracted period in which children's thinking is starkly egocentric (cf. Piaget 1997), reflected in their tendency to act as if everyone else knows all and only what they know (Wellman, Cross, \& Watson 2001). But the functions and applications of ToM continue to grow into the pre-adolescent and adolescent years, hand-in-hand with the EFs that facilitate its use (e.g., Carlson \& Moses 2001). For instance, the knowledge that two people can differ in their beliefs about a given situation might be used to condition how much information one of them chooses to share about the actions she next plans to take. While the relationship between strong ToM ability and EFs has not been investigated directly in bilingual adolescents, cognitive psychological studies of young children, pre-adolescents, adolescents, and adults have shown that ToM and EF continue to develop, in tandem, until they peak in most people's early twenties (cf. Apperly, Samson, \& Humphreys 2009). That this continued development could be reflected in language-based group differences of ToM/EF ability is therefore a marked possibility, and one that may have implications for the 
generation of reasonable expectations around the progression of certain academic skills that recruit ToM and EF.

Awareness of other minds - and attentiveness to the beliefs that those other minds holdis perhaps the key to the kind of social perspective taking (PT) that underlies writing that aims to and succeeds persuading, of which argument is a prototypical form. To gain agreement from a reluctant or recalcitrant party, that is to persuade, implies the recognition of another's position and an ability to cause it to change using any number of rhetorical or logical strategies (cf. Clark \& Delia 1976). Grasping that others may possess beliefs different from our own and that we can yet reach them through reasoned exposition of opinions and their roots points toward an additional benefit of bilingualism — one that straddles the line between the cognitive and the social. Lately research has begun to demonstrate that the increased social adeptness of bilingual children may at times compensate, in the classroom, for limited English proficiency, and may serve to help those students progress academically (e.g., Brisk 2012; Dray, Selman, \& Schulz 2009). For example, when fifth-grade students were asked to produce persuasive (sociallyinflected) essays, high social awareness effectively erased the negative impact of weaker literacy skills on the writing quality of LM students who were at the time still classified as English language learners (ELLs), relative to EO students (Dray et al. 2009). This finding indicates that the social sensitivities possessed by both ELLs and other LM students might be harnessed to augment their academic writing skills, a finding also supported by the documented tendency of current ELLs to import first- and second-person perspectives into tasks that predominantly call for the third person (Brisk 2012).

Apart from these limited studies examining the relationship between students' language background and their sociocognitive approaches to academic writing tasks, a more robust line of 
research has documented heightened metalinguistic awareness among bilinguals (Adesope et al. 2010). The concept of metalinguistic awareness refers to individuals' appreciation of language as itself a concept. That is, a person has acquired this notion when she demonstrates an ability to think and talk about structures of spoken and written language (e.g., Cazden 1974). A bilingual advantage in the development of metalinguistic awareness has been reported in school-age children using a variety of methods that require divorcing language forms from their typical functions (e.g., Bialystok, Luk, \& Kwan 2005, studying first-graders; Cummins, 1978, studying third- and sixth-graders; Feldman \& Shen 1971, studying kindergarteners; Francis 1999, studying second-, fourth-, and sixth-graders). For example, the arbitrariness of language task (Osherson \& Markman 1974), which asks elementary-age children to consider whether it would be possible to call the sun "the moon" and the moon "the sun," and what inferences would follow from that new habit, has a natural affinity with experiences frequently lived by bilingual children, who must apply two (arbitrary) labels to most of the objects they engage with every day. Monolingual children adhere to the Principle of Contrast, a heuristic guiding them to assume that a novel form has a novel meaning (Clark 1987); children acquiring two languages must and do quickly come to see that words and objects, phrases and functions, bear only a conventional, rather than an essential, relation to one another (e.g., Rosenblum \& Pinker 1983).

That words and phrases could be adopted for or adapted to specific purposes is where metalinguistic awareness gets its hold on academic outcomes. For example, Bialystok and colleagues (2005) showed that irrespective of whether bilingual children were learning to read in two different writing systems (e.g., in Hebrew and in English) or in two languages using the same writing system (e.g., in Spanish and in English), some specific literacy skills such as nonword decoding transferred from one language to the other. In light of evidence of this kind of 
skill transfer, it is worth exploring whether older children who know two languages could utilize skills developed through their complex linguistic experiences in conversation when engaging in literacy-related activities as well, such as the evaluation and construction of written arguments for an imagined set of readers.

\section{Arguing With Perspectives}

In response to the Common Core State Standards (NGAC 2010), and the growing belief among researchers and practitioners that arguing and debating can help children learn by seeing how knowledge is acquired and refined, discussion-based classroom instructional approaches

have been promoted in recent years (Murphy, Wilkinson, Soter, Hennessey, \& Alexander 2009). These approaches typically emphasize the need to acknowledge and assume other students' perspectives, and frequently translate into improvements in written argumentation (e.g., Kuhn et al. 2016; Reznitskaya et al. 2007), of which PT itself is a key component. Such findings are encouraging given that direct argumentative writing instruction often emphasizes structural and evidentiary components, to the exclusion of the many ways in which perspectives are in fact crucial to the presentation of a strong argument (cf. Reznitskaya et al. 2007).

In the context of one program utilizing in-class debates, Kuhn and colleagues (2016) showed recently that the interplay between an author's adopted perspective and her incorporation of others' perspectives in written argument becomes more sophisticated in the sixth and seventh grades. Word Generation (WordGen), another discussion-and-debate-based curriculum that encourages students to engage with a variety of plausible perspectives on polemical issues (Snow, Lawrence, \& White 2009), has been found to have positive impacts on student performance as well, both on social PT skill and on reading comprehension (Jones et al. 2016). In WordGen, students read texts that, while age-appropriate, are not simple in language or in 
content, in order to support their developing deep reading comprehension skills and their learning of domain-general academic vocabulary (Snow et al. 2009).

Interestingly, even given the linguistic complexity of the curricular readings LM students have proved particularly receptive to WordGen, which was designed to support the development of three identified predictors of deep reading comprehension: academic language, PT, and complex reasoning (LaRusso et al. 2016). Quasi-experimental and cluster randomized studies of the original version of WordGen showed significant improvements in students' knowledge of the academic words taught (Snow et al. 2009), especially for students from LM homes (Lawrence, Capotosto, Branum-Martin, White, \& Snow 2012). A follow-up analysis in one large district showed that the learning advantage of LM students was strongest immediately after reclassification as fully English proficient, and declined to the point that their gains matched EO students' gains only four years after reclassification (Hwang, Lawrence, Mo, \& Snow 2015). In other words, something about the WordGen experience seemed to be particularly propitious for engaging English learners and promoting their learning. This raises the question whether English learners show stronger gains than their EO peers in other WordGen tasks as well, in particular the curricular writing, and why this would be the case.

LaRusso and colleagues (2016) demonstrated that in addition to the more expectable effects that academic language and complex reasoning had on the development of deep reading comprehension (as measured by the Global Integrated Scenario-based Assessments, GISA:

O’Reilly \& Sabatini 2013; Sabatini, O’Reilly, Halderman \& Bruce 2014a, b), PT on its own explained some of the variance in a large sample of fourth through eighth grade students' GISA scores. That study used a new family of PT assessments, the Social Perspective-Taking Acts Measure (SPTAM: Diazgranados, Selman, \& Dionne 2015), which has since been revised to a 
new version (SPTAM-R: Kim, LaRusso, Hsin, Selman, \& Snow 2016), to measure PT in action: students were confronted with social dilemmas and asked to give advice to different participants, e.g., both bullies and victims, or both rule-breakers and witnesses, in the form of short written responses. While that research discovered a link between social PT and reading comprehension, it is not yet known whether and how social PT may be connected to argumentative writing development — neither in the general population nor specifically in the population of LM students.

\section{Research Aims}

The present study hypothesizes that bilingual children's writing should display advanced PT skills, as compared to the writing of their monolingual peers - despite the persistent gap in writing competence typically found between the LM population and their EO counterparts. This hypothesis draws on findings documented in educational research and cognitive psychology, as described above, and relies on the proposition that the modes of linguistic interaction of LM students have positive consequences for a cognitive stance toward other minds (i.e., in ToM development and, later, perspective taking) that may be manifested in their argumentative writing. The current research contributes to the small but growing body of work that links PT with literacy but goes beyond existing findings by addressing writing rather than reading and by focusing on the LM student population.

We therefore conducted a series of exploratory analyses on an existing set of data, essays written by students in the context of the WordGen curriculum, to ask our main research question: Does the persuasive writing of LM students display more PT than that of comparable EO students? Utilizing the coding scheme from the validated SPTAM(-R) measure, which has been shown to be reliable in reflecting individual differences among students in their ability to use 
social PT (cf. Kim et al. 2016), we assessed the degree of sophistication of PT evident in the writing students produced at the end of each curricular unit. Given the relationship between literacy skills and PT as measured by the SPTAM-R itself (LaRusso et al., 2016) — namely that PT skill explains unique variance in deep reading comprehension growth - we also investigated whether students' performance on the formal SPTAM-R measure itself related to the essays that they wrote within the intervention.

\section{Methods}

\section{Participants}

Forty-one LM students in Grades 4-6 in urban schools in the Northeastern US comprised the focal sample, exhausting the students classified as formerly limited English proficient (FLEP) in 19 classrooms in the study where there was at least one such student. Students classified as FLEP were studied here in order to minimize the influence that linguistic limitations would have on the LM students' ability to use PT. Given that FLEPs show persistent writingrelated difficulties throughout their schooling, their writing can still be expected to be weaker than that of similar EO students. Each LM student was then paired with an EO student using variable optimal matching (cf. Steiner \& Cook 2011) for classroom, sex, and free/reduced lunch status (FRL), to minimize the difference between the samples on the dimensions of demographics and instructional experiences. Variable optimal matching may pair the same EO student to two different LM students if she is the best match to them both; this was necessary for just two of the sample's 41 LM students. Academic performance data on a state standardized test in English Language Arts (ELA) from the sample were also gathered. Table 1 shows the breakdown of the sample by grade and summarizes the students' ELA test scores.

\section{Program}


The WordGen intervention is a Tier-1 curriculum, that is, it is designed for use in mainstream classrooms as a component of core instructional practices. It is comprised of a 24week sequence of curricular units meant to be used across content areas (i.e., in English language arts, math, science, and social studies classes). In each new unit a dilemma or discussable question is posed (e.g., "Should students be paid to do well in school?" or "Should everyone learn a second language?"), encouraging engaged reading of informative texts, class-wide discussion and debate, and a final "taking-a-stand" essay in which students are invited to articulate and defend their own position on the unit's question. It is the responses to this final piece which are the focus of the present study: fourth and fifth graders in classrooms where WordGen is fully implemented write twelve taking-a-stand essays per year (the fourth- and fifthgrade units are 10 days each), while sixth through eighth graders write 24 , one at the end of each week-long unit.

\section{Procedure}

Essays written by LM students in the context of WordGen unit responses were compared with matched EO students' essays from Grade 4 through Grade 6, in order to obtain a developmental perspective. Ultimately each student contributed between one and thirteen essays, for a total of 479 essays in the sample: EO students contributed an average of 6.16 essays $(S D=3.5)$, and LM students contributed an average of 5.20 essays $(S D=3.4)$. Since students were paired using variable optimal matching, we also examined whether in each pair the LM and EO student contributed a comparable number of essays. On average the difference between the number of essays contributed by each student in a pair was less than $1, M=0.90$, which across the sample was not statistically significant, paired $t(40)=1.51, p>.13$. Finally, language status was not associated with significant differences in essay length as measured by sum of word 
tokens (i.e., the sheer number of words per essay, including repeated words), $M(\mathrm{EO})=68.12$; $M(\mathrm{LM})=66.63$; Welch's $t(463.83)=-0.47, p>.64$, nor as measured by minimal terminable units (commonly termed T-units, a measure of student writing length using units "minimal as to length, and grammatically capable of being terminated with a capital letter and a period:" Hunt 1965, p. 37), $M(\mathrm{EO})=5.88 ; M(\mathrm{LM})=5.62 ;$ Welch's $t(459.77)=-0.82, p>.41$.

The essays were transcribed in CHAT format to prepare them for subsequent analysis using the Computerized Language Analysis (CLAN) program, originally designed for research with spoken language corpora from the Child Language Data Exchange System (MacWhinney 2000); in the original transcription process the essays were also coded for spelling, capitalization, and grammatical errors. The essays were then scored by two trained research assistants for sophistication of PT using a coding scheme developed to analyze responses to social scenarios administered as part of the SPTAM (Diazgranados et al. 2015; codebook available from the authors upon request). The SPTAM coding distinguishes three PT levels: the least sophisticated, acknowledgment, tallies mentions of unique agents or actors; a level above this, articulation, tallies explicit statements of thoughts, beliefs, preferences, and orientations to action; and finally, most challengingly, positioning characterizes an agent as reflective of a position or norm. For example, in the sentence, "Lou felt discouraged by her exam score because she was accustomed to getting all As," "Lou" is an acknowledged agent, "felt discouraged..." articulates her perspective, and Lou is positioned as feeling the way she does "because" of her past experiences. Each unique acknowledgment (ACK), articulation (ART), and positioning (POS) per essay was coded as such, giving rise to a wide range of simple summed composites across the whole 
sample as revealed by CLAN frequency analyses: ${ }^{1}$ students used between 0 and 27 types of PT in their essays, $M(\mathrm{n}(\mathrm{ACK})+\mathrm{n}(\mathrm{ART})+\mathrm{n}(\mathrm{POS}))=7.19, S D=3.5$. An example of a transcribed and coded essay is provided in the appendix as Figure 1.

A series of models were built to answer the two main research questions: is LM status (positively) predictive of PT use in fourth- through sixth-grade students' argumentative essay writing? and is adolescent students' spontaneous use of PT in these curricular writings related to the formal measure of PT derived from the SPTAM (Diazgranados et al. 2015)? In particular, we first generated a raw composite (i.e., sum) score, adding types of acknowledgment, articulation, and positioning found in each essay. Then, to examine those two levels of PT that were used regularly — acknowledgment and articulation — we standardized the values and tested their relationship to language status. We also generated a score of seized opportunities (SSO), seeking the number of acknowledged actors per essay whose perspectives were not articulated, to operationalize students' sensitivity to the perspectival opportunity presented by introducing another person into their argument. For each essay, the SSO was obtained by subtracting the rate of articulation use from the rate of acknowledgment use: a higher SSO indicates more missed opportunities to articulate an acknowledged perspective and thereby enrich the value of having introduced that perspective. An SSO of 2, for example, would be assigned to an essay in which a student acknowledged two actors for whom a perspective was not articulated, while an SSO of -1 would be assigned to an essay in which every acknowledged actor had her perspective articulated, and one more than once. Finally, we generated an articulation average, the mean

\footnotetext{
${ }^{1}$ Before completing these summary analyses, twenty percent of the essays were randomly selected to be coded independently by both coders, to allow for verification of interrater reliability, which proved good to excellent (Cronbach's $\alpha$ for acknowledgment $=0.88$; for articulation $=0.83$; for positioning too few tokens were found across essays to allow for computation of a reliability statistic).
} 
articulation use per student across all contributed essays, with which we sought to predict our formal measure of PT.

\section{Analysis and Results}

\section{Descriptive Characteristics}

As noted above, students used an average of 7.19 different PT types per essay. This figure breaks down as shown in Table 2 by grade, level of PT, and language status. The rates of acknowledgment, articulation, and positioning use appear to be comparable across the two language status groups. Positioning, the most sophisticated of the examined PT types, was almost never used-something that is to be expected in this group of young adolescents, given the sociocognitive complexity that positioning represents (Diazgranados et al. 2015) as well as its later emergence as demonstrated using a related measure (Kim et al. 2016). But the students did include a range of acknowledgment and articulation instances in the analyzed essays. Controlling for the wide range in essay length (8-224 words) produced the set of least-squares means shown in Table 3.

A final point of descriptive interest is that, for the subsample for whom social perspective-taking skill was formally measured (i.e., for whom SPTAM scores were available: $n$ $=54$ ), the LM sample began the year with positioning scores 0.62 of a standard deviation below the EO sample on average, $t(53)=-2.46, p<.02 .^{2}$ This indicates that any significant differences we find between the two language status groups in our full sample should be viewed in light of

\footnotetext{
2 The gap between the same groups of students' ability to enact perspective positioning was lessened by the end of the test year, to 0.47 of a standard deviation, $t(53)=-1.78, p<.09$, a finding that supports the sample studied here being representative of the larger sample in the CCDD project. This is because LM students have been found to improve more than EO students on positioning when participating in the Word Generation curriculum, in contrast to control students not exposed to the curriculum (see Kim et al. 2016).
} 
weaker formally assessed PT at the beginning of the academic year.

\section{Overall PT Use in Essays}

To investigate the relationship between language status and PT in argumentative writing, we began by building an intercept-only model to predict the variation in composite PT scores across the sample. The intercept-only model was a good fit to the data, $\beta_{\text {intercept }}=-0.04, t=-0.61$, $p<.001$, adjusted $r^{2}=0.18$. Adding two random effect terms-one matching each LM student with her classroom-, sex-, and FRL status-matched EO counterpart and the other representing the topic addressed in each essay_improved the model fit significantly $\left(\chi^{2}(1)=34.03, p<.001\right)$, while the PT coder's identity did not alter the fit of the model. We then serially incorporated our fixed-effect terms, sex and grade, and also controlled for essay length. While grade did not add significantly more explanatory power to the model, $\beta_{\text {grade }}=-0.02, t=-0.13, p>.8$, sex did; female students used more PT than male students, $\beta_{\text {female }}=0.43, t=3.11, p<.01$. Controlling for essay length in words generated a significantly improved model fit as well, $\chi^{2}(1)=222.20, p$ $<.001$.

The model predicts composite PT use well using pair codes, sex, essay length, and essay topic; we then sought effects of language status by adding an additional fixed effect term to the model. Language status did improve the model fit, $\chi^{2}(1)=7.12, p<.03$, contributing a negative parameter estimate associated with EO status, $\beta_{\mathrm{EO}}=-0.16, t=-2.41, p<.03$; that is, being an English-only student predicted less use of PT overall. In other words, LM students' writing exhibited more PT than that of matched EO students when essay length was controlled for. The final model of the composite PT data explains 55\% of the variation in composite PT use.

Next we explored whether a certain PT level carried the difference between the LM and the EO student writers. In these analyses and all those that follow, we set aside perspective 
positioning, as it appears developmentally beyond the reach of most of the students in Grades 4 6, at least in the context of these long-form, unconstrained essays. Specifically, only 40 of the essays in our sample, or $8.4 \%$, displayed any positioning whatever, and of those only 5 used positioning more than once. Modeling acknowledgment and articulation separately revealed that LM and EO students' essays differed not in the number of actors acknowledged but in the number of perspectives articulated. While including a language status term in the model predicting acknowledgment did not improve model fit over the base model, $\chi^{2}(1)=0.92, p>.3$, it did in the model predictive of articulation use, $\chi^{2}(1)=4.82, p<.03$. In this model EO status was associated with significantly fewer articulation types per essay than LM status, $\beta_{\mathrm{EO}}=-0.16, t$ $=-2.22, p<.001$.

\section{Score of Seized Opportunities}

Given the parity in acknowledgment scores by participant across groups and the significant disparity in articulation scores, our next step was to analyze the sample's SSOs to determine whether within essays LM students took up more opportunities to articulate acknowledged perspectives than EO students did. Because each SSO is computed by subtracting the number of perspectives articulated in each essay from the number of actors acknowledged, where a given actor can have more than one perspective ascribed to her, a higher score is indicative of fewer articulated perspectives relative to the number of actors introduced (i.e., acknowledged). The mean SSO for the sample, collapsing over language status, was $-0.31, S D=$ 0.10 , indicating that students did tend to articulate at least one perspective for each actor they introduced. As predicted, there was a numerically larger difference between acknowledgment and articulation rates in the EO students' essays, $M=-0.20, S E=0.13$, than there was in the LM students' essays, $M=-0.46, S E=0.16$. That is, the LM students' lower mean SSO reflects their 
tendency to articulate more perspectives per mentioned actor than EO students do. To properly estimate the effect of language status on this difference in light of our other variables of interest, we standardized the SSOs across the sample and built models parallel to those constructed for the sum of all three PT types. As before, there was a significant effect of essay length on our outcome variable, and in this case longer essays were associated with a smaller SSO: students who wrote longer essays took up more opportunities to articulate acknowledged perspectives than students who wrote shorter essays, $\beta_{\text {length }}=-0.18, p<.001$. Also similarly, language status emerged as a predictor of SSOs, though this time it was only marginally significant: EO students wrote essays earning a higher SSO than LM students did, $\beta_{\mathrm{EO}}=0.15, p<.1$, indicating that $\mathrm{EO}$ students' use of actors in these essays tended to be marginally less sophisticated than that of LM students.

\section{Relationship to Formally Measured PT Skill}

We also sought any link between the SPTAM-R scores for articulation and positioning that students had obtained at the beginning of the school year and our articulation outcome, for the reduced sample for which the relevant data existed, $n$ essays $=377$. First, we ran the winning model from the large data set on this reduced sample and obtained analogous results: EO students were less likely than LM students to use articulation in their essays, although the language status parameter estimate was only marginally significant, $\beta_{\mathrm{EO}}=-0.16, p<.07$. Incorporating the SPTAM-R positioning scores improved the model fit significantly, $\chi^{2}(1)=$ $6.64, p<.04$ and uncovered a stronger effect of language status, $\beta_{\mathrm{EO}}=-0.21, p<.02$. The positioning score itself contributed a positive parameter estimate that was marginally significant, $\beta_{\text {SPTAM-Rpositioning }}=0.10, p<.07$, indicating that students who used perspectives more sophisticatedly in the formal measure at the outset tended to articulate more actors' perspectives 
in their essays throughout the school year. There was, however, no significant interaction between language status and incoming SPTAM-R positioning score in predicting articulation in the essays.

The students completed an alternative form of the SPTAM-R at the end of the academic year. We tested two possible relationships between the incidence of articulation in the essays and the positioning score that students obtained on the year-end SPTAM-R, given the differences observed between the two language groups in the sample on positioning at the beginning of the year. First we tested whether the average number of articulation types (the "articulation average," a mean by participant, adjusted for essay lengths) that each student used in her essays throughout the year would predict her SPTAM-R positioning outcome. A model was fit with sex and language status as categorical predictors and articulation average as a continuous predictor, as well as the pair code as a grouping variable. While the intercept was significant, suggesting adequate variation in the data to detect effects of other factors, none of these predictors contributed a significant parameter estimate, and hence the data considered here cannot explain end-of-year SPTAM-R positioning scores in this sample. Further examination of the data using correlational analyses, however, revealed that this was due to there being almost no relationship between SPTAM-R positioning outcomes and essay articulation averages in the EO sample, $r(37)=-0.03, p>.8$, while there was a moderately strong and significant correlation between the variables in the LM sample, $r(36)=.33, p<.05$. LM students who had a higher articulation average in their WordGen essays throughout the year were also those who ended up with higher SPTAM-R positioning scores at the year's end (see Figure 2 below). In a separate set of models, we also tested whether students' articulation averages predicted the changes in students' SPTAM$\mathrm{R}$ positioning scores between the beginning and the end of the year, but they did not for either 
language status group.

\section{Discussion}

The analyses reported here show a reliable difference between students from EO homes and from LM homes in their propensity to use perspective articulation in taking-a-stand essays, when controlling for essay length. That is, even though LM students characteristically have not had the benefit of as much exposure to English-language print materials as their EO peers, they were found to bring to bear a larger number of personal perspectives in the context of persuasive essays, where those perspectives can serve to strengthen the argument presented. Correlational analyses additionally revealed that initial strength in formally-measured PT skills translated into more PT use in the persuasive essay context throughout the year, but that at the end of the year LM students who had used more PT in their essays continued to bring those skills to bear on the SPTAM-R, whereas EO students did not. Below we discuss how the relationship between social PT and the development of written argumentation skill may be a promising point of growth for LM students, the links and missing links between SPTAM-R and PT in persuasive essays, and the role that curricula like WordGen may play in fostering PT development in students from LM homes.

The relative strengths in PT skills that we have documented in a sample of FLEP students are distinct from those identified elsewhere in the literature. The present findings were not generated using laboratory-based assessments, nor self-report questionnaires, both of which fall outside of typical and authentic classroom activities. Instead, the taking-a-stand essays analyzed here were produced as a regular component of a Tier-1 curricular intervention that is aligned with the standards currently in place for the majority of U.S. school systems. Given that one of the goals of such standards is to teach students - both EO and LM students - to become proficient in 
argumentation, it is important to consider how the findings reported here, which focus not on the usual measures of argumentation but instead on social PT within a written argument, relate to that goal.

Instruction in argumentative writing often focuses on the structure of the argument on the whole and on the assembly of evidence within that structure, but what this emphasis overlooks is the large role that PT plays at several points in the process of crafting a written argument. The first is the point of deciding to write an argument: in the professional world, arguments are often presented in response to a genuine or perceived polemic and so shaped by the perspectives of multiple interested parties (cf. Shanahan \& Shanahan 2008), but writing an argument in the context of a classroom curriculum is colored by the frequently clashing perspectives of teacher and student, especially in the middle grades, and may be well served by students recognizing the teacher's perspective on and purpose for that exercise. Another three points of perspectival inflection relate in a more direct way to the content of argument itself. An author may benefit from keeping in mind toward whom the argument is directed, adjusting her tone, syntax, and lexical choices to maximize the rhetorical appeal of her text. But more than this, keeping the hypothetical reader's mind in mind and viewing the argument from her perspective can support the author in selecting what evidence to present (cf. Leyva, Hopson, \& Nichols 2012) supplementing rather than recapitulating that which the reader believes would favor the author's position. And thinking about what a reader knows and believes also paves the way for anticipation and preemption of counterarguments, where the author sees how and why the reader might object to her main line of argument. Situating an argument among the myriad alternative positions that another might take is one strong mark of a sophisticated argument — and of one that stands a chance at surviving criticism. 
Yet the majority of the students in this study did not use the most sophisticated form of social PT that we sought to identify, namely perspective positioning. It is interesting that even in the sixth grade most students do not take advantage of the persuasive power of positioning: they certainly have the cognitive ability of ToM and the linguistic tools of subordinate clauses and causal language needed to realize this kind of PT. Moreover, impact analyses of a randomized controlled trial of the curriculum have shown that upper-elementary and middle-school students do use positioning in the SPTAM-R, and that their facility with positioning improves with WordGen engagement (Jones et al., 2016). It appears that in a task like the SPTAM-R, which explicitly asks students to adopt multiple perspectives, their ability or inclination to justify the attribution of those perspectives (i.e., to position them) is stronger than it is in a more free-form argumentation task like the essays analyzed in the present study. This may be because even importing external points of view into the taking-a-stand essays already goes a step beyond the task requirement: to engage in positioning, a student would have to (1) introduce an actor, (2) articulate the actor's perspective, and (3) position that perspective. In contrast, in the SPTAM-R, the focal actor is already introduced, so that it takes only two steps to get from (1) articulation to (2) positioning. Both activities are complex, but that complexity surfaces PT skills differently. Perspective articulation may not appear to be a deeply sophisticated act in writing, but it indicates that students even as young as the fourth grade understand that other individuals have thoughts and feelings different from their own, and that those different thoughts and feelings are relevant to responses to an argumentative claim. In other words, the precursor to actively positioning individuals as possessors of mental states that arise out of their personal history is to articulate those mental states in the first place, in the context of a written argument. Given the value of perspective positioning to argumentation, it is encouraging that LM students have not 
only met but surpassed EO students in the use of that precursor.

Indeed, while several previous studies have documented a bilingual advantage in cognitive PT - that is, in ToM ability - this is the first to identify such an advantage in social PT, a skill embedded in, and sustaining of, advanced social practices, and one that puts perspectives to use. Bilingual individuals' constant practice in managing dual stores of linguistic knowledge, aligning dual stores of conceptual mappings, and anticipating interlocutors' communicative needs may promote an orientation to multiple points of view that manifests itself in social PT tasks as well as argumentation. It is not only in the context of long-form writing that social PT is relevant to the development of a rich cognitive and social life. As students encounter individuals with different sets of experiences and beliefs from their own, they will be asked to interpret those individuals' perspectives and give advice on the basis of the same.

This is in effect what the SPTAM-R measure captures, as students write short recommendations to people occupying various roles in contentious situations. We found that SPTAM-R positioning scores from the beginning of the academic year-before students had had a significant amount of exposure to the WordGen curriculum-predicted PT use in their essays throughout the academic year. But articulation scores on the SPTAM-R did not predict any of the PT measures in the essays, perhaps because of the SPTAM-R's relatively constrained structure. This disparity deserves further investigation, especially in light of the fact that LM students' articulation averages correlated with their year-end SPTAM-R positioning scores, while EO students' did not. Was this due to students' engagement with PT-related tasks? Did the LM students respond more favorably and reliably to opportunities to apply social PT in their academic work because it recruited a practiced skill of theirs in an otherwise challenging setting? Given that SPTAM-R positioning scores at the end of the year were correlated with the essay PT 
in the LM but not in the EO student group, it may be the case that LM students are more consistent in their recruitment of their PT skills whenever they are potentially useful (i.e., in the SPTAM-R and in essays), whereas EO students have a larger toolkit to draw from (e.g., using PT in SPTAM-R and using evidence or academic language in essays). These hypotheses will be addressed in planned research testing cognitive and social PT in a new sample, analyzing students' argumentative writing alongside a fuller picture of their relevant set of skills, including those aspects of argumentation that are most salient to each individual.

While without a control group we cannot isolate effects of the WordGen curriculum from other features of the present study sample, the curriculum - focused on discussion, debate, and the consideration of issues from diverse perspectives - was explicitly designed to draw out multiple points of view. Given the difficulty LM students often have with language-related exercises in school, particularly those that are relatively unconstrained in form, it is encouraging that this study has detected a relative strength in their writing, which not only matched EO students' skills but surpassed them on some measures. In their written arguments these LM students were evidently more inclined than their EO peers to apply the lessons of WordGen's heavy emphasis on the critical nature of multiple perspectives, familiar as they are with the concept in their everyday lives. In addition, WordGen offers a fair amount of scaffolding for growing writers' use of the language and structure of argumentation, which may help those LM students who still struggle somewhat with English vocabulary and syntax. Nevertheless, without any direct measures of students' engagement with particular aspects of the curriculum, it is difficult to say which of these features, if any, gave rise to the LM students' advantage on this task.

\section{Limitations}


The findings reported here are not without limitations. A small sample size and the lack of data points for each of the supplementary measures for every student should be remedied as much as possible in future work, once the nearly 15,000 student essays already collected have been transcribed for analysis. On the other hand, student absenteeism is a genuine issue, especially in urban public schools, and so missing data is to be expected in a representative sample of students. Relatedly, we were unable to obtain fine-grained information about the LM students' first- and second-language proficiency, as well as what those students' home languages were, information that may have provided some insight into why essay lengths were so variable across the sample. That all of the LM students in this study were classified as FLEP rather than being current LEPs naturally limits the generalizability of the reported findings to that population of LM students, but this, too, is a gap we plan to fill in future work.

This research is also limited in somewhat more substantive ways. There was no investigation into other characteristics of the students' arguments, such as language-based measures like lexical diversity, structural measures such as discourse organization, or argument features like the presence of warrants connecting claims to evidence or the deployment of counterarguments. Each of these will enrich in distinct ways future analyses of the role that social PT plays in students' developing written argumentation skill. In future work, for example, we plan to investigate whether the relation that students' claims have to the data and warrants they supply may be reflective of their experiences in their linguistic community, that is, whether LM students use more explicit language relating claims to other argument components because they understand that others may not automatically make the connections that they do. In addition, we were unable to test the impact of the WordGen curriculum on students' writing, given that all of our data were drawn from treatment schools; however, we are currently 
analyzing PT in essays collected in both treatment and control schools, and we anticipate that those analyses will enrich our understanding of the role that WordGen plays in fostering social PT, especially in the FLEP and LEP student populations. Finally, there is more work to do in understanding the phenomenon of PT itself, and the continuum between cognitive ability and social skill that it represents. We expect to enhance the granularity of the PT analysis itself by separating mental-state talk (e.g., "believe," "understand") from externalizing mental-state attribution (e.g., "love," "try"). But we also plan to situate students' PT use in writing within a richer picture of their PT-related skills — not only social and cognitive but linguistic as well.

\section{Conclusion}

Curricula such as WordGen that ask students to consider multiple perspectives on a single issue appear to be propitious for the academic and intellectual growth of LM students, and should be further tested for their particular utility in fostering that growth. LM students, despite making gains on some standardized measures, often continue to lag behind in more sophisticated academic language mastery (e.g., August \& Hakuta 1997); if writing tasks involving social PT are an oasis of relative competence then they should be utilized more widely. The cognitive and social benefits available to bilingual children are reasonably well understood by the cognitive development research community, but evidence that those advantages might be manifested in the classroom is fairly scarce. In contributing new knowledge about how bilingual students bring their experiences, implicitly, to bear in their academic work, this study has suggested a new dimension to the bilingual advantage and more opportunities to learn how bilinguals' experiences shape their cognition as well as their academic futures. 


\section{References}

Adesope, O. O., Lavin, T., Thompson, T., \& Ungerleider, C. (2010). A systematic review and meta-analysis of the cognitive correlates of bilingualism. Review of Educational Research, 80, 207 - 245. doi:10.3102/0034654310368803

Apperly, I. A., Samson, D., \& Humphreys, G. W. (2009). Studies of adults can inform accounts of theory of mind development. Developmental Psychology, 45, 190 - 201. doi:10.1037/a0014098

August, D., \& Hakuta, K. (Eds.) (1997). Improving schooling for language-minority children: A research agenda. Washington, DC: National Academies Press. doi:10.2307/3587914

August, D., Carlo, M., Dressler, C., \& Snow, C. (2005). The Critical Role of Vocabulary Development for English Language Learners. Learning Disabilities Research \& Practice, 20(1), 50 - 57. doi:10.1111/j.1540-5826.2005.00120.x

Battistich, V., Solomon, D., Kim, D., Watson, M., \& Schaps, E. (1995). Schools as Communities, Poverty Levels of Student Populations, and Students’ Attitudes, Motives, and Performance: A Multilevel Analysis. American Educational Research Journal, 32, 627 658. doi:10.3102/00028312032003627

Bialystok, E., Craik, F. I. M., \& Luk, G. (2012). Bilingualism: Consequences for mind and brain. Trends in Cognitive Sciences, 16(4), 240-250. doi: 10.1016/j.tics.2012.03.001

Bialystok, E., Luk, G., \& Kwan, E. (2005). Bilingualism, Biliteracy, and Learning to Read: Interactions Among Languages and Writing Systems. Scientific Studies of Reading, 9(1), 43 - 61. doi:10.1207/s1532799xssr0901_4

Brisk, M. E. (2012). Young Bilingual Writers' Control of Grammatical Person in Different Genres. The Elementary School Journal, 112, 445 - 468. doi:10.1086/663733 
Carlson, S. M., \& Moses, L. J. (2001). Individual differences in inhibitory control and children's theory of mind. Child Development, 72, 1032 - 1053. doi:10.1111/1467-8624.00333

Cazden, C. B. (1974). Play and metalinguistic awareness: One dimension of language experience. The Urban Review, 7(1), 28 - 39. doi:10.1007/bf02223202

Chan, K. T. (2004). Chinese-English bilinguals' theory-of-mind development (Unpublished doctoral dissertation). University of Toronto, Toronto, Canada.

Clark, E. V. (1987). The principle of contrast: A constraint on language acquisition. In B. MacWhinney (Ed.), Mechanisms of language acquisition (pp. 1 - 33). Hillsdale, NJ, England: Lawrence Erlbaum Associates, Inc. doi:10.4324/9781315798721

Costa, A., Hernández, M., Costa-Faidella, J., \& Sebastián-Gallés, N. (2009). On the bilingual advantage in conflict processing: Now you see it, now you don't. Cognition, 113(2), 135 - 149. doi:10.1016/j.cognition.2009.08.001

Cummins, J. (1978). Bilingualism and the Development of Metalinguistic Awareness. Journal of Cross-Cultural Psychology, 9(2), 131 - 149. doi:10.1177/002202217892001

de Bruin, A., Treccani, B., \& Sala, S. D. (2015). Cognitive Advantage in Bilingualism An Example of Publication Bias? Psychological Science, 26(1), 99 - 107. doi:10.1177/0956797614557866

Deuchar, M., \& Quay, S. (1999). Language choice in the earliest utterances: a case study with methodological implications. Journal of Child Language, 26, 461 - 475. doi: $10.1017 / \mathrm{s} 0305000999003852$

Diazgranados, S., Selman, R. L., \& Dionne, M. (2015). Acts of social perspective taking: A functional construct and the validation of a performance measure for early adolescents. Social Development, 25, 572 - 601. doi:10.1111/sode.12157 
Dobbs, C. L. (2014). Signaling organization and stance: academic language use in middle grade persuasive writing. Reading and Writing, 27, 1327 - 1352. doi:10.1007/s11145-0139489-5

Dray, A. J., Selman, R. L., \& Schultz, L. H. (2009). Communicating with intent: A study of social awareness and children's writing. Journal of Applied Developmental Psychology, 30(2), 116 - 128. doi:10.1016/j.appdev.2008.11.003

Feldman, C., \& Shen, M. (1971). Some language-related cognitive advantages of bilingual fiveyear-olds. The Journal of Genetic Psychology, 118, 235 - 244.

doi:10.1080/00221325.1971.10532612

Foster, M. A., Lambert, R., Abbott-Shim, M., McCarty, F., \& Franze, S. (2005). A model of home learning environment and social risk factors in relation to children's emergent literacy and social outcomes. Early Childhood Research Quarterly, 20(1), 13 - 36.

doi:10.1016/j.ecresq.2005.01.006

Francis, N. (1999). Bilingualism, writing, and metalinguistic awareness: Oral - literate interactions between first and second languages. Applied Psycholinguistics, 20, 533 561. doi:10.1017/s014271649900404x

Frantz, R. S., Starr, L. E., \& Bailey, A. L. (2015). Syntactic Complexity as an Aspect of Text Complexity. Educational Researcher, 44, 387 - 393. doi:10.3102/0013189x15603980

Genesee, F., Boivin, I., \& Nicoladis, E. (1996). Talking with strangers: A study of bilingual children's communicative competence. Applied Psycholinguistics, 17, 427 - 442. doi: $10.1017 / \mathrm{s} 0142716400008183$

Goetz, P. J. (2003). The effects of bilingualism on theory of mind development. Bilingualism: Language and Cognition, 6, 1 - 15. doi:10.1017/s1366728903001007 
Gonzalez, J. E., \& Uhing, B. M. (2008). Home Literacy Environments and Young Hispanic Children's English and Spanish Oral Language A Communality Analysis. Journal of Early Intervention, 30(2), $116-139$.

Graham, S., \& Perin, D. (2007). What We Know, What We Still Need to Know: Teaching Adolescents to Write. Scientific Studies of Reading, 11, 313 - 335. doi:10.1080/10888430701530664

Hunt, K. W. (1965). Grammatical Structures Written at Three Grade Levels. NCTE Research Report No. 3. Retrieved from http://eric.ed.gov/?id=ED113735

Hwang, J. K., Lawrence, J. F., Mo, E., \& Snow, C. E. (2015). Differential effects of a systematic vocabulary intervention on adolescent language minority students with varying levels of English proficiency. International Journal of Bilingualism, 19, 314 - 332. doi:10.1177/1367006914521698

Jones, S. M., LaRusso, M., Kim, J., Kim, H. Y., Selman, R. Uccelli, P., Barnes, S., Donovan, S., \& Snow, C. (2016, under review). Experimental Effects of Word Generation on Vocabulary, Academic Language, Perspective Taking, and Reading Comprehension in High Poverty Schools.

Kim, H. Y., LaRusso, M., Hsin, L., Selman, R., \& Snow, C. (2016, under review). Social Perspective Taking: Construct, Measurement, and Relations with Academic Performance and Engagement.

Kovács, Á. M. (2009). Early bilingualism enhances mechanisms of false-belief reasoning. Developmental Science, 12(1), 48 - 54. doi:10.1111/j.1467-7687.2008.00742.x Kuhn, D., \& Crowell, A. (2011). Dialogic Argumentation as a Vehicle for Developing Young Adolescents’ Thinking. Psychological Science, 22, 545 - 552. 
doi:10.1177/0956797611402512

Kuhn, D., \& Udell, W. (2003). The Development of Argument Skills. Child Development, 74, 1245 - 1260. doi:10.1111/1467-8624.00605

Kuhn, D., Hemberger, L., \& Khait, V. (2016). Tracing the Development of Argumentive Writing in a Discourse-Rich Context. Written Communication, 33(1), 92 - 121. doi:10.1177/0741088315617157

Kuhn, D., Zillmer, N., Crowell, A., \& Zavala, J. (2013). Developing Norms of Argumentation: Metacognitive, Epistemological, and Social Dimensions of Developing Argumentive Competence. Cognition and Instruction, 31, 456 - 496. doi:10.1080/07370008.2013.830618

LaRusso, M., Kim, H. Y., Selman, R., Uccelli, P., Dawson, T., Jones, S., Donovan, S., \& Snow, C. (2016). Contributions of Academic Language, Perspective Taking, and Complex Reasoning to Deep Reading Comprehension. Journal of Research on Educational Effectiveness, 9, 201 - 222. doi:10.1080/19345747.2015.1116035

Lawrence, J. F., Capotosto, L., Branum-Martin, L., White, C., \& Snow, C. (2012). Language proficiency, home-language status, and English vocabulary development: A longitudinal follow-up of the Word Generation program. Bilingualism: Language and Cognition, 15, 437 - 451. doi:10.1017/s1366728911000393

Lee, O., Quinn, H., \& Valdés, G. (2013). Science and Language for English Language Learners in Relation to Next Generation Science Standards and with Implications for Common Core State Standards for English Language Arts and Mathematics. Educational Researcher, 42, 223-233. https://doi.org/10.3102/0013189X13480524

Leyva, D., Hopson, S., \& Nichols, A. (2012). Reading a Note, Reading a Mind: Children's 
Notating Skills and Understanding of Mind. Reading and Writing, 25, 701 - 716. doi:10.1007/s11145-011-9296-9

Llosa, L., Beck, S. W., \& Zhao, C. G. (2011). An investigation of academic writing in secondary schools to inform the development of diagnostic classroom assessments. Assessing Writing, 16, 256 - 273. doi:10.1016/j.asw.2011.07.001

MacWhinney, B. (2000). The CHILDES project: Tools for analyzing talk (3 ${ }^{\text {rd }}$ ed.). Mahwah, NJ: Lawrence Erlbaum Associates. Retrieved from http://childes.psy.cmu.edu/manuals/CLAN.pdf

Mancilla-Martinez, J., \& Lesaux, N. K. (2011). Early home language use and later vocabulary development. Journal of Educational Psychology, 103, 535 - 546. doi:10.1037/a0023655

Martin-Rhee, M. M., \& Bialystok, E. (2008). The development of two types of inhibitory control in monolingual and bilingual children. Bilingualism: Language and Cognition, 11, 81 93. doi:10.1017/s1366728907003227

Matuchniak, T., Olson, C. B., \& Scarcella, R. (2014). Examining the text-based, on-demand, analytical writing of mainstreamed Latino English learners in a randomized field trial of the Pathway Project intervention. Reading and Writing, 27, 973 - 994. doi:10.1007/s 11145-013-9490-z

McQuillan, J. (2006). The effects of print access and print exposure on English vocabulary acquisition of language minority students. The Reading Matrix, 6(1). Retrieved from http://www.academia.edu/download/8655844/article.pdf

Murphy, P. K., Wilkinson, I. A. G., Soter, A. O., Hennessey, M. N., \& Alexander, J. F. (2009). Examining the effects of classroom discussion on students' comprehension of text: A meta-analysis. Journal of Educational Psychology, 101, 740 - 764. 
doi:10.1037/a0015576

National Governors Association Center for Best Practices \& Council of Chief State School Officers. (2010). Common Core State Standards. Washington, DC: Authors.

Newell, G. E., Beach, R., Smith, J., VanDerHeide, J., Kuhn, D., \& Andriessen, J. (2011). Teaching and Learning Argumentative Reading and Writing: A Review of Research. Reading Research Quarterly, 46(3), 273 - 304. doi:10.1598/RRQ.46.3.4

O’Reilly, T., \& Sabatini, J. (2013). Reading for understanding: How performance moderators and scenarios impact assessment design. ETS Research Report Series, 2013(2), i - 47. doi:10.1002/j.2333-8504.2013.tb02338.x

Osherson, D. N., \& Markman, E. (1974). Language and the ability to evaluate contradictions and tautologies. Cognition, 3(3), 213 - 226. doi:10.1016/0010-0277(74)90009-2

Piaget, J. (1997). Child's Conception of the World: Selected Works (Vol. 1). Oxon, UK: Routledge. doi:10.4324/9781315006215

Prior, A., \& Macwhinney, B. (2010). A bilingual advantage in task switching. Bilingualism: Language and Cognition, 13, 253 - 262. doi:10.1017/S1366728909990526

Qu, L., Low, J. J. W., Zhang, T., Li, H., \& Zelazo, P. D. (2016). Bilingual advantage in executive control when task demands are considered. Bilingualism: Language and Cognition, 19(2), 277-293. doi:10.1017/S1366728914000376

Reznitskaya, A., Anderson, R. C., \& Kuo, L. (2007). Teaching and Learning Argumentation. The Elementary School Journal, 107, 449 - 472. doi:10.1086/518623

Rosenblum, T., \& Pinker, S. A. (1983). Word magic revisited: Monolingual and bilingual children's understanding of the word-object relationship. Child Development, 54, 773 780. doi: $10.2307 / 1130064$ 
Sabatini, J., O’Reilly, T., Halderman, L., \& Bruce, K. (2014a). Broadening the scope of reading comprehension using scenario-based assessments: Preliminary findings and challenges. International Journal Topics in Cognitive Psychology, 114, 693 - 723. doi: $10.4074 / \mathrm{s} 0003503314004059$

Sabatini, J., O’Reilly, T., Halderman, L., \& Bruce, K. (2014b). Integrating scenario-based and component reading skill measures to understand the reading behavior of struggling readers. Learning Disabilities Research \& Practice, 29, 36 - 43. doi:10.1111/1drp.12028

Scaltritti, M., Peressotti, F., \& Miozzo, M. (2015). Bilingual advantage and language switch: What's the linkage? Bilingualism: Language and Cognition, FirstView, 1 - 18. doi:10.1017/S1366728915000565

Shanahan, T., \& Shanahan, C. (2008). Teaching disciplinary literacy to adolescents: Rethinking content-area literacy. Harvard Educational Review, 78(1), 40 - 59. doi:10.17763/haer.78.1.v62444321p602101

Snow, C. E., Lawrence, J. F., \& White, C. (2009). Generating Knowledge of Academic Language Among Urban Middle School Students. Journal of Research on Educational Effectiveness, 2, 325 - 344. doi:10.1080/19345740903167042

Snow, C.E., \& Uccelli, P. (2009). The challenge of academic language. In D.R. Olson \& N. Torrance (Eds.), The Cambridge handbook of literacy (pp. 112 - 133). New York: Cambridge University Press. doi:10.1017/cbo9780511609664.008

Steiner, P. M., \& Cook, D. (2011). Matching and propensity scores. In T. D. Little (Ed.), The Oxford Handbook of Quantitative Methods (pp. 237 - 259). Oxford: Oxford University Press. doi:10.1093/oxfordhb/9780199934874.013.0013

Toulmin, S. (1958). The Uses of Argument. Cambridge, UK: Cambridge University Press. 
doi:10.1017/cbo9780511840005

Uccelli, P., Dobbs, C. L., \& Scott, J. (2013). Mastering Academic Language Organization and Stance in the Persuasive Writing of High School Students. Written Communication, 30(1), 36 - 62. doi:10.1177/0741088312469013

Verreyt, N., Woumans, E., Vandelanotte, D., Szmalec, A., \& Duyck, W. (2016). The influence of language-switching experience on the bilingual executive control advantage. Bilingualism: Language and Cognition, 19, 181 - 190. doi:10.1017/S1366728914000352

Walsh, M. E., Madaus, G. F., Raczek, A. E., Dearing, E., Foley, C., An, C., ... Beaton, A. (2014). A New Model for Student Support in High-Poverty Urban Elementary Schools: Effects on Elementary and Middle School Academic Outcomes. American Educational Research Journal, 51(4), 704 - 737. doi:10.3102/0002831214541669

Wellman, H. M., Cross, D., \& Watson, J. (2001). Meta-Analysis of Theory-of-Mind Development: The Truth about False Belief. Child Development, 72, 655 - 684 . doi:10.1111/1467-8624.00304

Wilcox, K. C. (2011). Writing across the curriculum for secondary school English language learners: A case study. Writing \& Pedagogy, 3(1), 79 - 111. doi:10.1558/wap.v3i1.79 Yang, H., \& Yang, S. (2017). Are all interferences bad? Bilingual advantages in working memory are modulated by varying demands for controlled processing. Bilingualism: Language and Cognition, 20(1), 184 - 196. doi:10.1017/S1366728915000632 


\section{Figure 1. Example of transcribed and coded essay.}

Lines beginning with ${ }^{*} \mathrm{STU}$ : are lightly but systematically corrected student writing, in this example produced by a student in Grade 5. Lines beginning with $\circ$ prs: contain the PT coding,

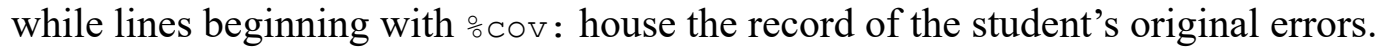

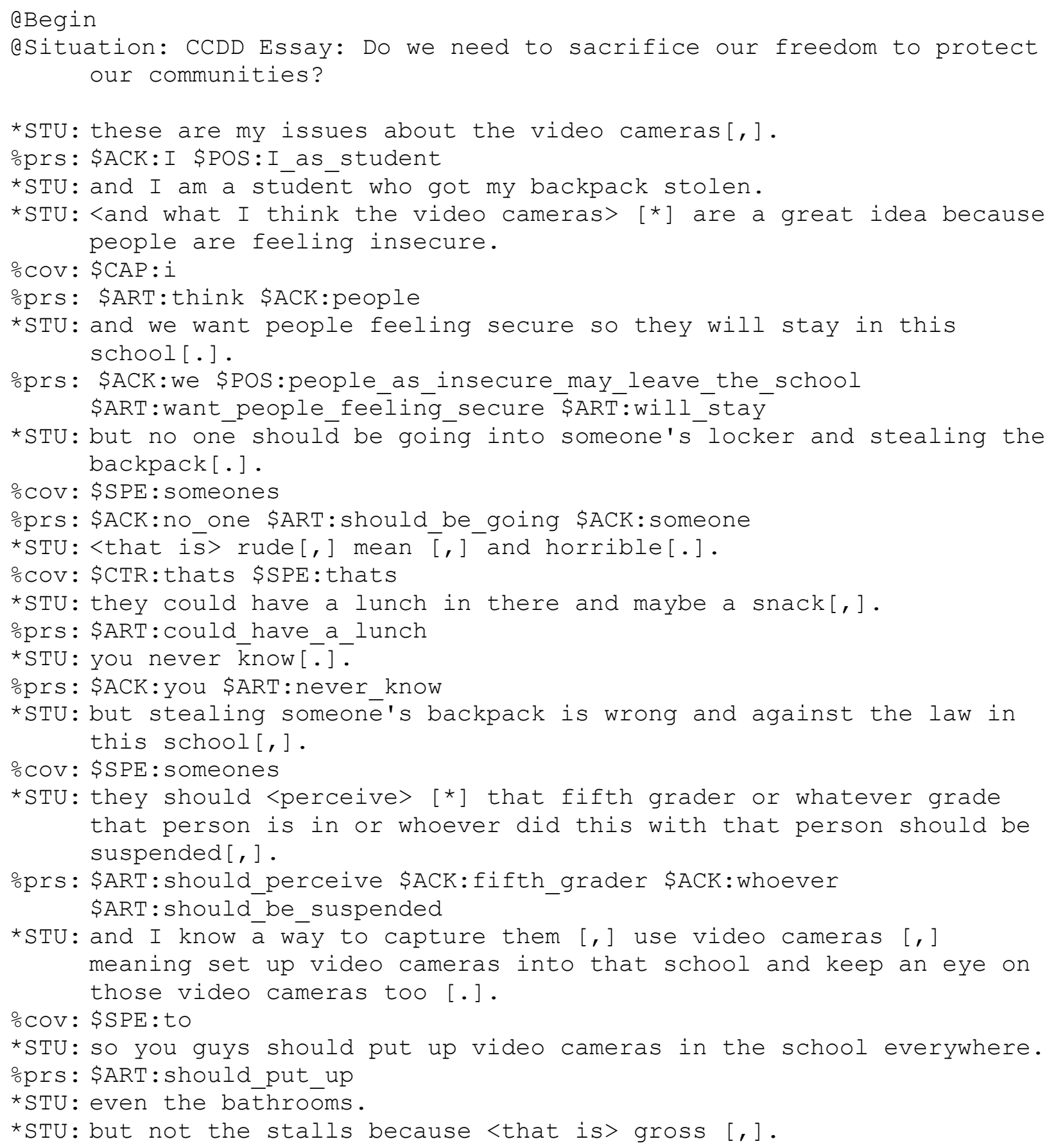


\%COV: \$CTR: thats \$SPE: thats \$SPE:gros

*STU: and you should monitor them so you can see who that person is $[\cdot]$.

oprs: \$ART:should_monitor_them

*STU: last thing.

*STU: my perspective is to use video cameras so students feel more secure [.].

oprs: \$ART:use_video cameras \$ART:feel_more_secure

*STU: and that is what I suspect [*] you to do [.].

\% COV: \$CAP: i

oprs: \$ACK: suspect

aEnd 
Figure 2. Correlation between end-of-year SPTAM-R positioning score and articulation average in essays

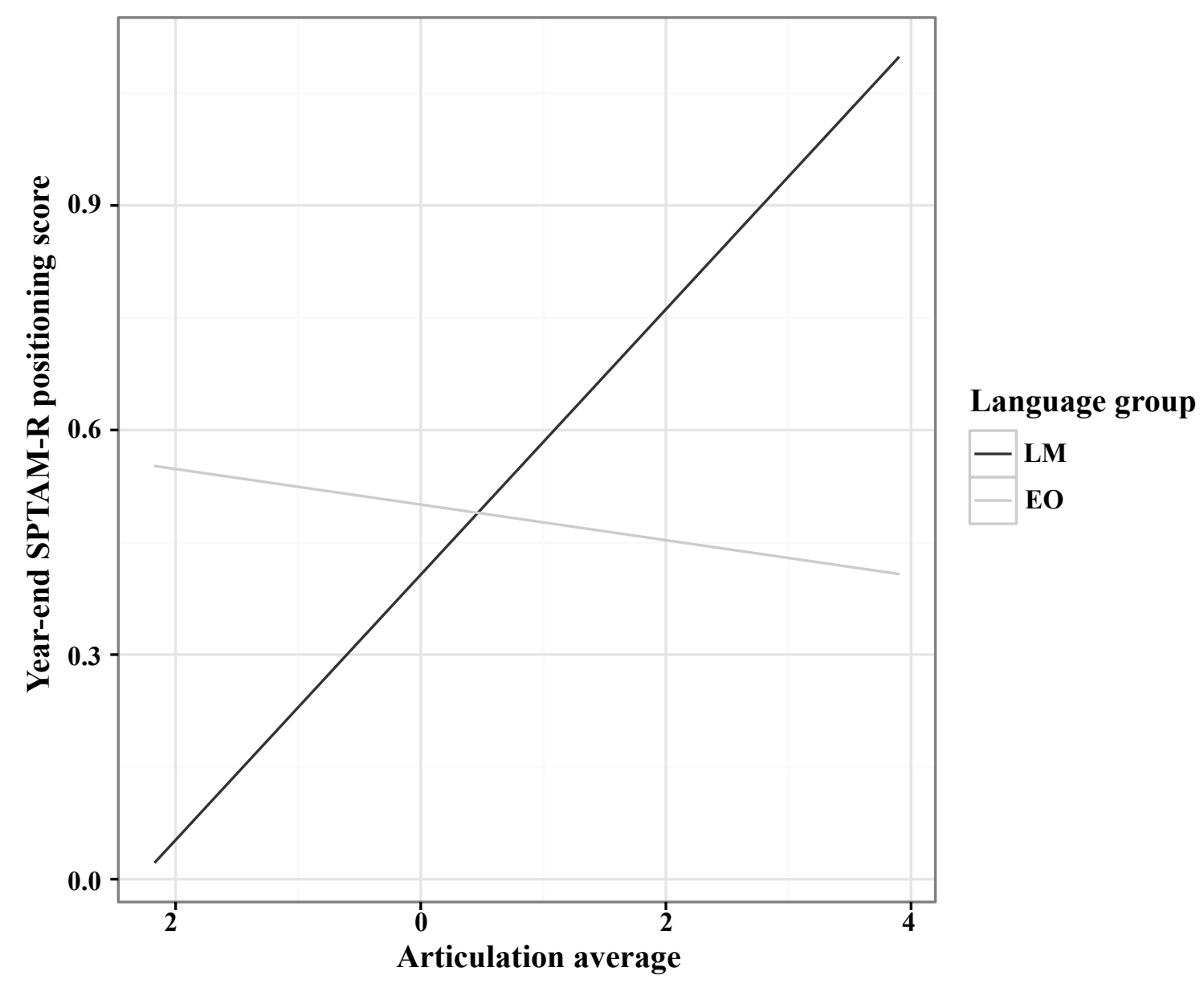

